\title{
Editorial
}

Psychotherapy and Psychosomatics

\section{Beyond DSM-IV Bereavement Exclusion Criterion E for Major Depressive Disorder}

\author{
Guy Chouinard ${ }^{a, b}$ Virginie-Anne Chouinard ${ }^{d}$ Emmanuelle Corruble ${ }^{c}$ \\ a Department of Psychiatry, Clinical Psychopharmacology, McGill University Health Centre, Montreal, Que., \\ Canada; bepartment of Psychiatry, Saint-Antoine Hospital, Paris, and 'Department of Psychiatry, INSERM U669, \\ Paris XI University, Bicêtre University Hospital, Assistance Publique-Hôpitaux de Paris, Le Kremlin Bicêtre, France; \\ ${ }^{\mathrm{d}}$ Massachusetts General Hospital/McLean Adult Psychiatry Residency Training Program, Harvard Medical School, \\ Boston, Mass., USA
}

There are two issues facing the DSM-V in the revision of the criteria for major depressive disorder (MDD), the first being the concept of DSM-III [1] criterion A inclusion symptoms for major depressive episode (MDE), which has recently been addressed by Fava et al. [2], Lichtenberg and Belmaker [3] and Bech [4]. The second concerns bereavement criterion $\mathrm{E}$, which often leads to exclusion from MDE. The rationale behind criterion $\mathrm{E}$ was that symptoms of bereavement-related sadness resemble those of major depression without the presence of MDD. Bereavement is the only stressful life event (SLE) which is an exclusion criterion for a DSM axis I diagnosis, unless depressive symptoms associated with bereavement last longer than 2 months or meet the bereavement descriptive $\mathrm{E}$ criterion for major depression. Several authors have questioned the validity of excluding bereavement from major depression when all other inclusion criteria are met [5-8]. SLE, including bereavement, have been found to contribute to, initiate and maintain MDD [9-17]. More recently, we reported that DSM-IV bereavement-excluded subjects were more severely depressed than MDE subjects without bereavement, and at least as severely depressed as MDE subjects with bereavement [18]. At this time, the DSM-V is proposing to delete bereavement exclusion criterion $\mathrm{E}$ for major depression (www.DSM5.org). In the present ar- ticle, we propose to revise DSM-IV bereavement exclusion and keep the $\mathrm{V}$ code for bereavement as suggested by Paula Clayton [19]. In addition, in the event that criterion $\mathrm{E}$ is deleted, we believe that criterion A for major depression should be revised to require at least 7 of the 9 criterion $\mathrm{A}$ inclusion symptoms for MDE in all types of MDD, which would satisfy the concerns raised by Lichtenberg and Belmaker [3] and Bech [4] about the overinclusiveness of criterion A, leading to overdiagnosis of MDE. Adjusting the number of inclusion symptoms of criterion A reinforces the dimensional approach to depression initiated by the DSM-III (1980) and DSM-III-R (1987). To avoid a 'single catchall entity' diagnosis of MDE [3], depression subtypes can be used, including bereavement depression. Now is the time to reevaluate depression subtypes and MDD, and allow subtypes for some of the welldefined stress event depressions.

\section{Bereavement and Major Depression}

Bereavement is known to be associated with high rates of MDE and of other major depressive syndromes [20-29]. Major depression is common during the first year of bereavement, with higher rates earlier in bereave-

\section{KARGER}

Fax +4161306 1234 E-Mail karger@karger.ch www.karger.com
(C) 2010 S. Karger AG, Base

0033-3190/11/0801-0004\$38.00/0

Accessible online at:

www.karger.com/pps
Guy Chouinard

RVH/Allan Memorial Institute

Clinical Psychopharmacology, McGill University Health Centre

1025 Pine Avenue West, Montreal, QC H3A 1A1 (Canada)

Tel. +1 514843 1672, Fax +1 514843 2898, E-Mail va.chouinard@gmail.com 
ment and lower rates throughout the year following the loss of a loved one $[21,22,27,30,31]$. In a prospective study of 109 widows and widowers, $35 \%$ of the widows and widowers were depressed after 1 month of bereavement, $25 \%$ at 4 months and $17 \%$ at 13 months, and $45 \%$ were depressed at one point in the year following the death of their spouse $[21,22]$. In another study of 350 widows and widowers, $24 \%(\mathrm{n}=84)$ met DSM-III-R criteria for MDD after 2 months of bereavement, $23 \%$ ( $\mathrm{n}=$ 72 of 308$)$ after 7 months and $16 \%(n=46$ of 286$)$ at 13 months [20]. Several authors including Harlow et al. [27] $(n=136)$ and Bruce et al. [24] $(n=39)$ have shown similar increased rates of MDD in bereaved widows and widowers. These studies have mainly focused on spousal bereavement in older or elderly populations. In a later study ( $\mathrm{n}=328$ ), Zisook et al. [30] found a rate of minor depression in widows and widowers of $20 \%$ at 2 months after the loss, of $23 \%$ at 7 months and of $17 \%$ at 13 months. More recently, a high rate of suicidal ideation has been found in bereaved individuals [32-34]. Stroebe et al. [32] compared 60 widowed individuals to married individuals and found that widowed individuals had a greater risk of suicidal ideation, and a higher risk was shown particularly for widows. Suicidal ideation was more likely in bereaved individuals with a prior history of depression [34] and was associated with severe depressive scores [32, 34].

\section{Predictors of Major Depression in Bereavement}

Studies looking at factors predicting MDD in bereaved individuals did not report consistent results. Bereaved individuals with a prior history of MDD [30] or psychiatric illness $[35,36]$ are more likely or at least as likely to develop MDD [21, 22] compared to other bereaved individuals. Age has also yielded conflicting results: some studies have shown younger bereaved subjects being more likely to develop MDD [20,30], while others have reported an absence of association of age with MDD [21-23, 28, $37,38]$. Women have also been shown to be more likely $[24,38,39]$ or as likely to develop MDD [20-23, 28, 30, 37, 40] compared to men after the loss of a loved one. These differences may be due to varying study designs and sample populations. In genetic studies, the vulnerability of individuals to the depressogenic effects of SLE has been linked to the functional polymorphism in the promoter region of the serotonin transporter (5-HTT) [41, 42]. Individuals with the short alleles at the 5-HTT locus showed more major depression, depressive symptoms and suicid- al ideation associated with SLE than individuals without the short alleles.

\section{DSM Classifications and Bereavement}

The DSM classification of bereavement-related major depressive syndromes has evolved over time [43]. Before the DSM-III (1980) [1], the DSM-II (1968) [44] classified neurotic/reactive/bereavement depression as depressive neurosis and endogenous depression as manic-depressive illness, depressed type, related to the presence or absence of an SLE. In the DSM-III, depression following bereavement was described as uncomplicated bereavement ( $\mathrm{V}$ code) with no classification as a mental disorder, and when bereavement depression met MDE criteria, it was labelled complicated bereavement, which Wakefield et al. [45] proposed to replace by 'complicated bereavementtriggered depression'. In the DSM-IV (1994) [46], bereavement is defined as a V code (V62.82), meaning 'Other Conditions that May Be a Focus of Clinical Attention', and thus, despite the evidence that MDD is often associated with bereavement, major depression in bereaved individuals may not be recognized as a mental disorder. The DSM-IV bereavement exclusion is a leftover of the DSM-II classification of endogenous depression versus neurotic/ reactive depression, and thus excludes bereaved individuals, resembling DSM-II neurotic/reactive depression, from the diagnosis of MDD unless depressive symptoms resemble those of DSM-II endogenous depression and last more than 2 months or there is 'marked functional impairment, morbid preoccupation with worthlessness, suicidal ideation, psychotic symptoms, or psychomotor retardation'. Therefore, individuals having 5 or more MDE inclusion symptoms of criterion A and showing all other inclusion criteria can be excluded from the diagnosis of MDD and only satisfy the bereavement $V$ code. This goes against the symptom-dimensional approach initiated by the DSM-III, which required 4 inclusion symptoms, and the DSM-III-R with 5 inclusion symptoms for major depression; this should be a major theoretical argument in favour of deleting criterion $\mathrm{E}$.

The rationale for bereavement exclusion was to prevent bereaved individuals who suffer from unpleasant, disturbing, but transient symptoms of depression from being diagnosed as having MDD. However, the risk of underestimating MDD in bereaved individuals is significantly greater and carries clinical consequences for individuals with a DSM axis I disorder. 


\section{DSM Axis I and SLE Including Bereavement}

The question is raised whether the DSM-IV is justified in separating bereavement from other SLE. Other SLE associated with major depression do not lead to exclusion from the diagnosis of MDD or any other axis I diagnosis. In their literature review, Zisook and Kendler [8] concluded that bereavement-related depression has more similarities than differences with MDD. Several authors $[5-8,47-49]$ have questioned the validity of excluding bereavement from major depression when all other criteria are met. In contrast, Wakefield et al. [45] proposed to extend the MDD bereavement exclusion to other losses after comparing the 1992 National Comorbidity Survey MDD bereavement exclusion cases ( $\mathrm{n}=56$ uncomplicated bereavement-triggered cases) to uncomplicated other-losstriggered cases $(n=174)$.

\section{Evidence from a French National Cross-Sectional Study}

Recently, we reported [18] - based on data from a French national cross-sectional study assessing major depressive symptoms and SLE, carried out between September 2003 and May 2004 - that bereaved individuals excluded from the DSM MDE diagnosis but satisfying all other MDE criteria represented $8.5 \%(n=1,521)$ of 17,988 self-referred individuals seeking treatment and meeting DSM MDE inclusion symptom criterion $\mathrm{A}$, and that $74.4 \%(n=13,337)$ of the 17,988 participants met the diagnosis of MDE. The methods have previously been described [18]. Briefly, the 1,521 subjects (8.5\%) identified as bereavement-excluded individuals, but meeting all other DSM criteria for MDE, were matched by age, gender, marital status, educational level and number of previous depressive episodes with controls coming from the same sample, but meeting all DSM-IV MDE criteria. The MDE module of the Mini-International Neuropsychiatric Inventory (MINI) structured interview [50] was used to complete the diagnostic criteria of DSM-IV MDE, consisting of at least 5 of $9 \mathrm{MDE}$ symptoms including 'depressed mood' or 'diminished interest or pleasure'. In addition, evaluators used the clinical description indicated in the DSM MDE bereavement exclusion to include patients with bereavement in the MDE group. The number of DSM MDE inclusion depressive symptoms of criterion A and the Montgomery-Åsberg Depression Rating Scale (MADRS) [51] assessed the severity of depression. SLE preceding the current depressive syndrome were identified using the Life Events Inventory (LEI) [52].

Compared to MDE patients from the same sample, bereavement-excluded individuals had significantly more MDE inclusion symptoms and greater severity of depression on the MADRS; we also found that bereaved MDE patients were significantly more depressed than nonbereaved MDE patients [18]. We concluded that there was a high risk of being excluded as bereaved individuals with MDE by physicians: $74.3 \%(1,789$ out of 2,408$)$ in case of general practitioners, and $25.7 \%$ (619 out of 2,408$)$ in case of psychiatrists, both using the MINI structured interview and the DSM MDE bereavement exclusion criterion E [18]. In a letter to the editor concerning those results, Clayton [19] wrote: 'It may be that the instructions are poorly written and that criterion $\mathrm{E}$ for major depression should be deleted, but the V code should remain.'

These results suggest that bereavement has specific effects on depression in both MDE bereaved patients and DSM bereavement-excluded individuals, thus providing support for the concept of depression subtypes put forward by Lichtenberg and Belmaker [3] and Bech [4]. We propose that bereavement depression be added as a depression subtype of MDD.

\section{Proposal for Diagnosing MDE in Bereaved Individuals}

In this paper, we present data to revise the DSM-IV MDE criteria for bereaved individuals. The proposal consists of using a threshold number of DSM-IV MDE criterion A inclusion symptoms to ensure the severity of depression and to satisfy the DSM-III-R dimensional approach. Bereavement-excluded subjects were divided into 2 groups according to the mean number of MDE inclusion depressive symptoms (6.8; min. 5 to max. 9), one group ( $\mathrm{n}=851)$ with 7 or more MDE symptoms and the other group $(n=670)$ with less than 7 MDE symptoms. Bereavement-excluded subjects with 7 or more $\mathrm{MDE}$ symptoms were found to have significantly $(p<0.0001)$ more of each of the 9 MDE symptoms and higher $(\mathrm{p}<$ 0.0001) mean total scores on MADRS items compared to those with less than $7 \mathrm{MDE}$ symptoms (Cochran-MantelHaenszel $\chi^{2}$ test and two-sample $t$ test) (table 1). Bereavement-excluded subjects with 7 or more MDE inclusion symptoms were also found to have significantly ( $\mathrm{p}<$ 0.0001 ) more of each of the $9 \mathrm{MDE}$ inclusion symptoms and higher mean scores on all MADRS items, including the total score, compared to MDE patients meeting all 
Table 1. Number and percentages of MDE symptoms, as well as MADRS and LEI scores, in bereavementexcluded individuals meeting all criteria for MDE except bereavement exclusion

\begin{tabular}{lllll}
\hline & $\begin{array}{l}\text { Individuals with } \geq 7 \\
\text { MDE symptoms } \\
(\mathrm{n}=851)\end{array}$ & $\begin{array}{l}\text { Individuals with }<7 \\
\text { MDE symptoms } \\
(\mathrm{n}=670)\end{array}$ & Test & $\mathrm{p}$ \\
\hline MDE symptoms (9 items) & & & & \\
Mean number \pm SD & $7.74 \pm 0.79$ & $5.61 \pm 0.73$ & $\mathrm{t}:-54.1$ & $<0.0001$ \\
Depressed mood (a) & $99.4 \%$ & $93.6 \%$ & $\chi^{2}: 41.7$ & $<0.0001$ \\
Diminished interest or pleasure (b) & $98.0 \%$ & $88.8 \%$ & $\chi^{2}: 55.8$ & $<0.0001$ \\
Weight disturbance & $63.4 \%$ & $28.9 \%$ & $\chi^{2}: 177.4$ & $<0.0001$ \\
Sleep disturbance & $94.5 \%$ & $73.9 \%$ & $\chi^{2}: 129.5$ & $<0.0001$ \\
Agitation/retardation & $86.8 \%$ & $52.1 \%$ & $\chi^{2}: 224.1$ & $<0.0001$ \\
Fatigue/loss of energy & $98.0 \%$ & $86.6 \%$ & $\chi^{2}: 72.8$ & $<0.0001$ \\
Worthlessness or excessive guilt & $87.3 \%$ & $49.1 \%$ & $\chi^{2}: 263.0$ & $<0.0001$ \\
Concentration/indecisiveness & $93.5 \%$ & $69.4 \%$ & $\chi^{2}: 152.1$ & $<0.0001$ \\
Death or suicidal thoughts & $52.5 \%$ & $18.5 \%$ & & $<0.0001$ \\
\hline MADRS (10 items) & & & $\mathrm{t}:-13.65$ & $<0.0001$ \\
MADRS total score (range: $0-50)$ & $33.53 \pm 7.1$ & $28.6 \pm 6.75$ & & \\
\hline
\end{tabular}

Symptom (a) or (b) must be present for the diagnosis of MDE.

Table 2. Number and percentages of MDE symptoms, as well as MADRS and LEI scores, in bereavementexcluded individuals meeting all criteria for MDE except bereavement exclusion with 7 or more MDE symptoms and in matched MDE subjects from the same sample

\begin{tabular}{lllll}
\hline & $\begin{array}{l}\text { Bereavement-excluded } \\
\text { individuals with } \geq 7 \text { MDE } \\
\text { symptoms ( }=851)\end{array}$ & $\begin{array}{l}\text { Matched subjects } \\
\text { with MDE (n=851) }\end{array}$ & Test & $p$ \\
& & & & \\
MDE symptoms (9 items) & $7.74 \pm 0.79$ & $6.56 \pm 1.19$ & $\mathrm{t}:-23.8$ & $<0.0001$ \\
Mean number & $99.4 \%$ & $95.6 \%$ & $\chi^{2}: 24.7$ & $<0.0001$ \\
Depressed mood (a) & $98.0 \%$ & $93.2 \%$ & $\chi^{2}: 23.0$ & $<0.0001$ \\
Diminished interest or pleasure (b) & $63.4 \%$ & $41.9 \%$ & $\chi^{2}: 78.5$ & $<0.0001$ \\
Weight disturbance & $94.5 \%$ & $83.2 \%$ & $\chi^{2}: 55.0$ & $<0.0001$ \\
Sleep disturbance & $86.8 \%$ & $68.4 \%$ & $\chi^{2}: 82.7$ & $<0.0001$ \\
Agitation/retardation & $98.0 \%$ & $93.7 \%$ & $\chi^{2}: 19.8$ & $<0.0001$ \\
Fatigue/loss of energy & $87.3 \%$ & $83.7 \%$ & $\chi^{2}: 93.3$ & $<0.0001$ \\
Worthlessness or excessive guilt & $93.5 \%$ & $29.3 \%$ & $\chi^{2}: 40.9$ & $<0.0001$ \\
Concentration/indecisiveness & $52.5 \%$ & & $\chi^{2}: 94.0$ & $<0.0001$ \\
Death or suicidal thoughts & & $29.9 \pm 6.66$ & $\mathrm{t}:-10.71$ & $<0.0001$ \\
\hline MADRS (10 items) & $33.53 \pm 7.1$ & &
\end{tabular}

Symptom (a) or (b) must be present for the diagnosis of MDE.

DSM-IV criteria for major depression (table 2). Logistic regression analysis was conducted in bereavement-excluded subjects $(\mathrm{n}=1,521)$ to predict 7 or more MDE symptoms, using age, gender, number of previous MDE, MADRS total scores, and LEI total scores as independent variables. Individuals with 7 or more MDE symptoms were significantly more likely to have higher MADRS total scores (OR: 1.10; 95\% CI: 1.08-1.12; $\chi^{2}=125.13$; $\mathrm{p}<$ 0.0001 ) and more previous MDE (OR: $1.10 ; 95 \%$ CI: $\left.1.006-1.21 ; \chi^{2}=4.29 ; \mathrm{p}=0.03\right)$. There were no significant 
differences in terms of age (OR: 0.997; 95\% CI: 0.99-1.005; $\chi^{2}=0.62 ; \mathrm{p}=0.42$ ), gender (OR: $1.17 ; 95 \%$ CI: 0.91-1.50; $\chi^{2}=1.61 ; \mathrm{p}=0.20$ ) or LEI scores (OR: $1.00 ; 95 \%$ CI: 0.99 $1.001 ; \chi^{2}=0.74 ; \mathrm{p}=0.38$ ).

\section{Conclusion}

The data presented here are in favour of a revised MDE bereavement exclusion criterion to include bereaved individuals with 7 or more MDE inclusion symptoms. The proposed new criterion could be easily determined via the criterion A inclusion symptoms, rather than by the DSM-IV clinical description of 'marked functional impairment, morbid preoccupation with worthlessness, suicidal ideation, psychotic symptoms, or psychomotor retardation', which, as noticed by Clayton [19], is 'poorly worded'. The new procedure would have the advantage of being easy to integrate into structured interview questionnaires such as the MINI and the Structured Clinical Interview for DSM-IV since MDE inclusion criterion symptoms are part of the questionnaire for establishing the diagnosis of MDD. It is interesting to note that the results from the logistic regression analysis identified a previous MDE episode as a predictor of the presence of 7 or more DSM-IV MDE inclusion symptoms in bereaved individuals, providing further support for this new approach. Thus, the new criterion for bereavement would include bereaved individuals who have at least $7 \mathrm{MDE}$ inclusion symptoms.

The concept presented here could be extended to the number of inclusion symptoms required for an MDE in all types of MDD. The DSM-V might require 7 instead of 5 out of the $9 \mathrm{MDE}$ inclusion symptoms of criterion A for MDE. Thus, the patients diagnosed with this new set of criteria would be closer to the more severely depressed MDD patients having participated in clinical trials carried out in the 1978-1990 period by one of the authors (G.C.) [53], and show less of the placebo responses seen in the more recent clinical trials.

The $\mathrm{V}$ code for bereavement could be maintained for those who do not meet the proposed inclusion criterion A symptom, and bereavement depression could be classified as a stress event subtype of MDD when bereaved subjects meet the new proposed inclusion criterion A. Lichtenberg and Belmaker [3] proposed 10 subtypes of depression, and Bech [4] kept 3 subtypes of stress event depression, but did not include bereavement depression. We propose the following 6 stress event MDD subtypes: (1) bereavement depression; (2) childhood trauma depression; (3) separation depression; (4) postpartum depression; (5) late-life depression, and (6) seasonal depression. These subtypes could be easily defined. This permits avoiding the 'single catchall entity' overinclusiveness and overdiagnosis of DSM-IV MDE criterion A as described by Lichtenberg and Belmaker [3].

\section{Conflicts of Interest}

G.C. has received consulting fees and honoraria within the last 5 years from Schering Plough, BioLineRx and Takeda. E.C. has received consulting fees and honoraria within the last 5 years from Servier, Sanofi-Aventis, Bristol Myers Squibb, Wyeth, Lilly, UCB Pharma, Eisai and Janssen-Cilag.

\section{References}

1 American Psychiatric Association: Diagnostic and Statistical Manual of Mental Disorders, ed 3 (DSM-III). Washington, American Psychiatric Association, 1980.

-2 Fava GA, Guidi J, Semprini F, Tomba E, Sonino N: Clinical assessment of allostatic load and clinimetric criteria. Psychother Psychosom 2010;79:280-284.

3 Lichtenberg P, Belmaker RH: Subtyping major depressive disorder. Psychother Psychosom 2010;79:131-135.

4 Bech P: The struggle for subtypes in primary and secondary depression and their modespecific treatment or healing. Psychother Psychosom 2010;79:331-338.
5 Zisook S, Shear K, Kendler KS: Validity of the bereavement exclusion criterion for the diagnosis of major depressive episode. World Psychiatry 2007;6:102-107.

6 6 Zimmerman M, McGlinchey JB, Chelminski I, Young D: Diagnosing major depressive disorder V: applying the DSM-IV exclusion criteria in clinical practice. J Nerv Ment Dis 2006;194:530-533.

7 Zimmerman M, Spitzer R: Psychiatric classification; in Sadock BJ, Sadock VA (eds): Kaplan and Sadock's Comprehensive Textbook of Psychiatry. Philadelphia, Lippincott Williams \& Wilkins, 2005, pp 1003-1034.

8 Zisook S, Kendler KS: Is bereavement-related depression different than non-bereavementrelated depression? Psychol Med 2007;37: 779-794.
9 Akiskal HS, McKinney WT Jr: Overview of recent research in depression: integration of ten conceptual models into a comprehensive clinical frame. Arch Gen Psychiatry 1975;32: 285-305.

10 Paykel ES, Tanner J: Life events, depressive relapse and maintenance treatment. Psychol Med 1976;6:481-485.

-11 Kendler KS, Karkowski LM, Prescott CA: Causal relationship between stressful life events and the onset of major depression. Am J Psychiatry 1999;156:837-841.

12 Kendler KS, Hettema JM, Butera F, Gardner CO, Prescott CA: Life event dimensions of loss, humiliation, entrapment, and danger in the prediction of onsets of major depression and generalized anxiety. Arch Gen Psychiatry 2003;60:789-796. 
13 Fava GA, Munari F, Pavan L, Kellner R: Life events and depression: a replication. J Affect Disord 1981;3:159-165.

14 Costello CG: Social factors associated with depression: a retrospective community study. Psychol Med 1982;12:329-339.

15 Kessler RC: The effects of stressful life events on depression. Annu Rev Psychol 1997;48: 191-214.

-16 Thomson KC, Hendrie HC: Environmental stress in primary depressive illness. Arch Gen Psychiatry 1972;26:130-132.

-17 Surtees PG, Miller PM, Ingham JG, Kreitman NB, Rennie D, Sashidharan SP: Life events and the onset of affective disorder: a longitudinal general population study. J Affect Disord 1986; 10:37-50.

$\checkmark 18$ Corruble E, Chouinard VA, Letierce A, Gorwood PA, Chouinard G: Is DSM-IV bereavement exclusion for major depressive episode relevant to severity and pattern of symptoms? A case-control, cross-sectional study. J Clin Psychiatry 2009;70:1091-1097.

19 Clayton PJ: V code for bereavement. J Clin Psychiatry 2010;71:359-360, author reply 360.

20 Zisook S, Shuchter SR: Depression through the first year after the death of a spouse. Am J Psychiatry 1991;148:1346-1352.

21 Clayton PJ, Halikas JA, Maurice WL: The depression of widowhood. Br J Psychiatry 1972; 120:71-77.

22 Clayton PJ: The clinical morbidity of the first year of bereavement: a review. Compr Psychiatry 1973;14:151-157.

23 Clayton PJ: The sequelae and nonsequelae of conjugal bereavement. Am J Psychiatry 1979; 136:1530-1534

24 Bruce ML, Kim K, Leaf PJ, Jacobs S: Depressive episodes and dysphoria resulting from conjugal bereavement in a prospective community sample. Am J Psychiatry 1990;147: 608-611.

-25 Breckenridge JN, Gallagher D, Thompson LW, Peterson J: Characteristic depressive symptoms of bereaved elders. J Gerontol 1986;41:163-168.

-26 Futterman A, Gallagher D, Thompson LW, Lovett S, Gilewski M: Retrospective assessment of marital adjustment and depression during the first 2 years of spousal bereavement. Psychol Aging 1990;5:277-283.

-27 Harlow SD, Goldberg EL, Comstock GW: A longitudinal study of risk factors for depressive symptomatology in elderly widowed and married women. Am J Epidemiol 1991;134: 526-538.
28 Turvey CL, Carney C, Arndt S, Wallace RB, Herzog R: Conjugal loss and syndromal depression in a sample of elders aged 70 years or older. Am J Psychiatry 1999;156:15961601.

29 Onrust SA, Cuijpers P: Mood and anxiety disorders in widowhood: a systematic review. Aging Ment Health 2006;10:327-334.

-30 Zisook S, Paulus M, Shuchter SR, Judd LL: The many faces of depression following spousal bereavement. J Affect Disord 1997; 45:85-94, discussion 94-95.

31 Maciejewski PK, Zhang B, Block SD, Prigerson HG: An empirical examination of the stage theory of grief. JAMA 2007;297:716723.

32 Stroebe M, Stroebe W, Abakoumkin G: The broken heart: suicidal ideation in bereavement. Am J Psychiatry 2005;162:2178-2180.

33 Prigerson HG, Bridge J, Maciejewski PK, Beery LC, Rosenheck RA, Jacobs SC, Bierhals AJ, Kupfer DJ, Brent DA: Influence of traumatic grief on suicidal ideation among young adults. Am J Psychiatry 1999;156: 1994-1995.

34 Szanto K, Prigerson H, Houck P, Ehrenpreis L, Reynolds CF 3rd: Suicidal ideation in elderly bereaved: the role of complicated grief. Suicide Life Threat Behav 1997;27:194-207.

35 Hays JC, Kasl S, Jacobs S: Past personal history of dysphoria, social support, and psychological distress following conjugal bereavement. J Am Geriatr Soc 1994;42: 712-718.

36 Nuss WS, Zubenko GS: Correlates of persistent depressive symptoms in widows. Am J Psychiatry 1992;149:346-351.

37 Clayton PJ, Herjanic M, Murphy GE, Woodruff R Jr: Mourning and depression: their similarities and differences. Can Psychiatr Assoc J 1974;19:309-312.

38 Chen JH, Bierhals AJ, Prigerson HG, Kasl SV, Mazure CM, Jacobs S: Gender differences in the effects of bereavement-related psychological distress in health outcomes. Psychol Med 1999;29:367-380.

-39 Thompson LW, Gallagher-Thompson D, Futterman A, Gilewski MJ, Peterson J: The effects of late-life spousal bereavement over a 30-month interval. Psychol Aging 1991;6: 434-441.

40 Clayton PJ: Bereavement and depression. Clin Psychiatry 1990;51(suppl):34-38, discussion 39-40.

41 Caspi A, Sugden K, Moffitt TE, Taylor A, Craig IW, Harrington H, McClay J, Mill J, Martin J, Braithwaite A, Poulton R: Influence of life stress on depression: moderation by a polymorphism in the 5 -HTT gene. Science 2003;301:386-389.
42 Kendler KS, Kuhn JW, Vittum J, Prescott CA, Riley B: The interaction of stressful life events and a serotonin transporter polymorphism in the prediction of episodes of major depression: a replication. Arch Gen Psychiatry 2005;62:529-535.

43 Lichtenthal WG, Cruess DG, Prigerson HG: A case for establishing complicated grief as a distinct mental disorder in DSM-V. Clin Psychol Rev 2004;24:637-662.

44 American Psychiatric Association: Diagnostic and Statistical Manual of Mental Disorders, ed 2. Washington, American Psychiatric Association, 1968.

45 Wakefield JC, Schmitz MF, First MB, Horwitz AV: Extending the bereavement exclusion for major depression to other losses: evidence from the National Comorbidity Survey. Arch Gen Psychiatry 2007;64:433440

46 American Psychiatric Association: Diagnostic and Statistical Manual of Mental Disorders, ed 4 (DSM-IV). Washington, American Psychiatric Association, 1994.

47 Kendler KS, Myers J, Zisook S: Does bereavement-related major depression differ from major depression associated with other stressful life events? Am J Psychiatry 2008; 165:1449-1455.

48 Karam EG, Tabet CC, Alam D, Shamseddeen W, Chatila Y, Mneimneh Z, Salamoun MM, Hamalian M: Bereavement-related and non-bereavement-related depressions: a comparative field study. J Affect Disord 2009;112:102-110.

49 Shear MK: Grief and depression: treatment decisions for bereaved children and adults. Am J Psychiatry 2009;166:746-748.

50 Lecrubier Y, Sheehan DV, Weiller E, Amorim P, Bonora I, Harnett-Sheehan K, Janavs J, Dunbar G: The Mini-International Neuropsychiatric Interview (MINI): a short diagnostic structured interview - reliability and validity according to the CIDI. Eur Psychiatry 1997;12:224-230.

- 51 Montgomery S, Åsberg M: A new depression scale designed to be sensitive to change. $\mathrm{Br} \mathrm{J}$ Psychiatry 1979;134:382-389.

52 Holmes TH, Rahe RH: The social readjustment rating scale. J Psychosom Res 1967;11: 213-218.

53 Chouinard G: The search for new off-label indications for antidepressant, antianxiety, antipsychotic and anticonvulsant drugs. J Psychiatry Neurosci 2006;31:168-176. 